Original research article

\title{
Noninfectious complications of acute stroke and their impact on hospital mortality in patients admitted to a stroke unit in Warsaw from 1995 to 2015
}

\author{
Michal A. Karlinski ${ }^{a}$, Jan P. Bembenek ${ }^{a}$, Anna Baranowska ${ }^{a}$, \\ Iwona Kurkowska-Jastrzebska ${ }^{a}$, Anna Czlonkowska ${ }^{a, b, *}$ \\ a 2nd Department of Neurology, Institute of Psychiatry and Neurology, Warsaw, Poland \\ ${ }^{\mathrm{b}}$ Department of Experimental and Clinical Pharmacology, Medical University of Warsaw, Poland
}

\section{A R T I C L E I N F O}

Article history:

Received 8 August 2017

Accepted 13 September 2017

Available online 21 September 2017

Keywords:

Acute stroke

Complication

Stroke unit care

Hospital mortality

\begin{abstract}
A B S T R A C T
Background: Medical complications often worsen the prognosis after stroke. Our aim was to investigate the association between particular noninfectious complications and hospital mortality of acute stroke patients admitted to an urban Polish stroke center, and changes in their occurrence from 1995 to 2015.

Methods: This is a retrospective analysis of 5174 consecutive patients admitted for acute ischemic stroke or cerebral hemorrhage to a Polish urban stroke center between 1995 and 2015. The occurrence of complications was reported for years 1995-2000 ( $n=883), 2001-2006$ $(n=1567), 2006-2010(n=1539)$ and 2011-2015 ( $n=1183)$. Odds ratios (OR) with $95 \%$ confidence interval $(95 \% \mathrm{CI})$ for stroke unit death were calculated after adjustment for age, congestive heart failure (CHF), pre-existing disability, stroke type and baseline neurological deficit in three different time periods.

Results: Over time there was a significant decrease in the occurrence of myocardial infarction (MI) $(2.2 \%, 1.4 \%, 1.0 \%$ and $0.3 \%$, respectively), exacerbated CHF $(4.6 \%, 5.1 \%, 2.6 \%$ and $2.0 \%$ ) and deep vein thrombosis (DVT) (4.6\%, 2.7\%, 1.2\% and 1.1\%). Adjusted odds for stroke unit death were increased by myocardial infarction (MI) (OR 17.5, 95\% CI: 8.5-35.7), exacerbated CHF (OR 15.0, 95\% CI: 9.8-23.0), pulmonary embolism (PE) (OR 11.5, 95\% CI: 6.1-21.6), gastrointestinal bleeding (OR 9.2, 95\% CI: 4.4-18.9) and recurrent stroke (OR 5.4, 95\% CI: $3.1-$ 9.3).

Conclusions: Over the last two decades Polish urban stroke units may have achieved a significant reduction of the occurrence of some noninfectious complications (i.e. MI, exacerbated CHF and DVT). However, the list of conditions associated with stroke unit mortality includes not only MI and exacerbated CHF but also PE, gastrointestinal bleeding and recurrent stroke.
\end{abstract}

(c) 2017 Published by Elsevier Sp. z o.o. on behalf of Polish Neurological Society.

\footnotetext{
* Corresponding author at: 2nd Department of Neurology, Institute of Psychiatry and Neurology, ul. Sobieskiego 9, 02-957 Warsaw, Poland.

E-mail address: czlonkow@ipin.edu.pl (A. Czlonkowska).

http://dx.doi.org/10.1016/j.pjnns.2017.09.003

0028-3843/@ 2017 Published by Elsevier Sp. z o.o. on behalf of Polish Neurological Society.
} 


\section{Introduction}

Despite significant reduction in age-standardized incidence in high-income countries and advances in treatment, the overall burden of stroke continues to increase making it one of the leading causes of death and disability worldwide [1]. This burden results not only from the brain damage but also from a variety of infectious and noninfectious complications [2,3]. Many of those complications are either fully preventable or can be effectively managed if recognized early [2]. It has been shown that increasing quality of acute stroke care decreases the risk of most medical complications [4]. One may expect that constant development and wide implementation of modern stroke care over the years has led to their a significant decrease of their occurrence. The lack of deleterious weekend effect on outcome after intravenous thrombolysis indirectly proves decent quality of contemporary acute stroke care in Poland but there are no studies that address complications [5]. Besides publications concerning early noninfectious complications of acute stroke in other countries are very heterogeneous in terms of definitions and reported occurrence [2-4,617], and infrequenty report changes over longer periods of time $[7,14,15]$ or the effect on outcome $[6,10-13,17]$.

The aim of our study was to investigate the association between particular noninfectious complications and hospital mortality in acute stroke and changes in their occurrence among patients admitted to an urban Polish stroke center between year 1995 and 2015.

\section{Material and methods}

\subsection{Population}

This is a retrospective registry-based analysis of consecutive acute stroke patients admitted to a single stroke center between July 1995 and December 2015. The center operates as a part of department of neurology and provides health services for a population of approximately 200,000-250,000 Caucasians living in a highly urbanized area (Southern Warsaw, Poland). The center consists of intensive stroke unit and early rehabilitation unit and has direct access to interventional neuroradiology, neurosurgery and rehabilitation wards.

\subsection{Methods}

The diagnosis of ischemic stroke or intracranial hemorrhage was routinely based on clinical symptoms and noncontrast brain computed tomography (CT) sometimes complemented or substituted with brain magnetic resonance. The event was considered acute if the onset of symptoms was within the last 7 days. Patients' data were prospectively collected in a detailed stroke registry. The registry was created in 1991 as a modification of the National Institute of Neurological and Communicative Disorders and Stroke Data Bank protocol, and was upgraded in subsequent years [18-20]. Briefly, collected data include information about patient's demographics, preexisting conditions and medications, diagnostic workup, the course of index stroke throughout hospital stay, stroke unit adverse events, stroke unit treatment and outcome at discharge to home, other ward or nursing home.

There were eight predefined complications: deep vein thrombosis (DVT), pulmonary embolism (PE), myocardial infarction (MI), exacerbated congestive heart failure (CHF), seizures, recurrent stroke, pressure sores and gastrointestinal bleeding. The diagnosis was usually made by the attending neurologist according to his best medical judgment. However, in many cases it had to be confirmed by additional examinations or by a relevant consultant (internal medicine specialist, cardiologist or surgeon). General criteria defining each abovementioned condition are listed in Table 1 . The information about occurrence of a particular complication during whole stroke unit stay was recorded in the registry as a nominal variable. Events that began before stroke and was ongoing at the time of admission to the stroke unit were not included.

Stroke severity was measured at admission and multiple times during stroke unit stay with the use of Scandinavian Stroke Scale (SSS) until year 2009 and National Institutes of Health Stroke Scale (NIHSS) later on. For the purpose of this analysis all SSS scores were converted to NIHSS using a validated equation [21]. The level of prestroke disability of any cause was measured with modified Rankin Scale (mRS).

Due to low absolute numbers of particular complications per year we decided to evaluate longitudinal changes between four consecutive time periods: (i) years 1995-2000, (ii) years 2001-2005, (iii) years 2006-2010 and (iv) years 2011-2015.

The paper follows Strengthening the Reporting of Observational Studies in Epidemiology guidelines [22].

\subsection{Ethics}

The registry was developed in concordance with the Declaration of Helsinki and was approved by the local Ethics Committee.

\subsection{Statistical analysis}

Categorical variables were presented as a number of valid observations and proportions calculated with exclusion of unknown values from the denominator. As the distribution of continuous variables was mostly non-normal, they were presented as a median with quartiles (1st quartile and 3rd quartile; Q1, Q3).

Comparisons between particular time periods were done using chi square test and Kruskal-Wallis test, as appropriate. Only if the overall test for significance was positive $(P<0.05)$, pairwise comparisons were made between the first time period (i.e. years 1995-2000) and each consecutive time period (e.g. years 1995-2000 vs. years 2011-2015). Additionally, similar comparisons were made between each following time period (i.e. years 2000-2005 vs. years 2006-2010 and years 2006-2010 vs. years 2011-2015). Such approach allows to minimize the risk of type I error without losing power by applying the Bonferroni correction.

Logistic regression was used to calculate odds ratios (ORs) with $95 \%$ confidence interval (95\% CI) for stroke unit death. Multivariable analyses were arbitrarily adjusted for age (as a continuous variable), CHF, lack of prestroke dependency (mRS 
Table 1 - Definitions of particular noninfectious complications recorded in the registry.

\begin{tabular}{|c|c|c|}
\hline Complication & Definition & Confirmation obtained from another specialist \\
\hline Deep vein thrombosis & $\begin{array}{l}\text { Clinical signs of vein thrombosis in at least one lower } \\
\text { extremity confirmed by ultrasound examination if } \\
\text { feasible. }\end{array}$ & Certified sonologist/radiologist or surgeon \\
\hline Pulmonary embolism & $\begin{array}{l}\text { Clinical suspicion confirmed by computed } \\
\text { tomography angiography. }\end{array}$ & Radiologist \\
\hline Myocardial infarction & $\begin{array}{l}\text { Electrocardiography and/or laboratory findings } \\
\text { (cardiac enzymes, including troponins) consistent } \\
\text { with the diagnosis of any type of myocardial } \\
\text { infarction. }\end{array}$ & Internal medicine specialist or cardiologist \\
\hline $\begin{array}{l}\text { Exacerbation of congestive } \\
\text { heart failure }\end{array}$ & Clinical diagnosis. & Internal medicine specialist or cardiologist \\
\hline Seizure & $\begin{array}{l}\text { At least one seizure of any type that was either } \\
\text { witnessed directly by medical staff, unambiguously } \\
\text { described by a non-medical witness or recorded on } \\
\text { electroencephalography, irrespectively patient's } \\
\text { history of epilepsy. }\end{array}$ & \\
\hline Recurrent stroke & $\begin{array}{l}\text { New onset of focal neurological deficit that cannot be } \\
\text { attributed to progression of the index brain infarct or } \\
\text { its hemorrhagic transformation that lasts more than } \\
24 \mathrm{~h} \text { and/or produces new lesion on neuroimaging. }\end{array}$ & \\
\hline Pressure sores & $\begin{array}{l}\text { New skin breaks or necrosis clearly resulting from } \\
\text { pressure or trivial trauma. }\end{array}$ & \\
\hline Gastrointestinal bleeding & $\begin{array}{l}\text { Clinical symptoms (i.e. hematemesis, coffee ground } \\
\text { emesis, melena or hematochezia not associated with } \\
\text { hemorrhoids). }\end{array}$ & Surgeon or internal medicine specialist \\
\hline
\end{tabular}

0-2 vs. 3-5), type of stroke (i.e. cerebral hemorrhage vs. ischemic stroke), baseline neurological deficit (NIHSS as a continuous variable).

$P$ values of $<0.05$ were considered statistically significant. Calculations were carried out using STATISTICA 12.0 software package (Stat Soft Inc., Tulsa, USA, 2013).

\section{Results}

\subsection{General characteristics}

The study included a total of 5174 acute stroke patients of whom 883 were admitted in years 1995-2000, 1567 in years 2001-2005, 1539 in years 2006-2010 and 1183 in years 20112015.

Throughout the studied period there was an overall trend toward higher median age (from 72 years to 76 years). The prevalence of hypertension, atrial fibrillation and prestroke dependency increased in years 2006-2010 and then remained stable, whilst the prevalence of diabetes became significantly higher only in years 2011-2015 (Table 2). The proportion of males, patients with ischemic stroke, CHF, coronary artery disease, previous MI or previous stroke, current smokers and excessive alcohol consumers did not change significantly over time (Table 2). Baseline neurological deficit decreased from median 11 NIHSS points in years 1995-2005 to 8 points in years 2006-10 and 7 points in years 2011-15. Median length of stroke unit stay shortened from 17 days in years 1995-2000 to 10-11 days in years 2001-2015, whilst the median number of days spent in intensively monitored bed fluctuated between 3 to 1 (Table 2). There was also a significant decrease in stroke unit mortality from $19-21 \%$ in years $1995-2005$ to $11-13 \%$ in years 2006-2015 (Table 2).

\subsection{Noninfectious complications}

The occurrence of MI decreased from $1.4-2.2 \%$ in years $1995-$ 2005 to $1.0 \%$ in years $2006-2010$ and then to $0.3 \%$ in years $2011-$ 2015 (Table 3). The proportion of patients experiencing exacerbation of CHF was also reduced from 4.6-5.1\% in years $1995-2005$ to $2.0-2.6 \%$ in years $2006-2015$ (Table 3). The occurrence of DVT decreased from $4.6 \%$ in years $1995-2000$ to $2.7 \%$ in years $2001-2005$ and then to $1.1-1.2 \%$ in years $2006-$ 2015. The occurrence of PE (1.2-1.4\%) or seizures (0.3-0.6\%) did not change significantly throughout the studied period (Table 3). Gastrointestinal bleeding was not observed in years 1995-2000, its occurrence increased to $1.7-1.9 \%$ in years $2001-$ 2010 and then dropped to $0.8 \%$ in years $2011-2015$. An opposite trend was observed in respect to pressure sores which were reported for $3.2 \%$ of patients in years $1995-2000$, then for 1.1$1.6 \%$ in years $2001-2010$, and again for $2.3 \%$ in years $2011-2015$ (Table 3). The proportion of patients having recurrent strokes fluctuated between $0.9 \%$ and $2.3 \%$ with peak values in years 2001-2005 and 2011-2015 (Table 3).

\subsection{Logistic regression}

Unadjusted logistic regression suggested that each investigated complication, except for DVT, increases odds for stroke unit death (Table 4). This was confirmed after adjustment for age, CHF, preexisting dependency, type of stroke and baseline neurological deficit for all complications with the exception of seizures and pressure sores (Table 4). The strongest predictors of hospital death were: MI (adjusted OR 17.5, 95\% CI: 8.5-35.7), exacerbated CHF (adjusted OR 15.0, 95\% CI: 9.8-23.0) and PE (adjusted OR 11.5, 95\% CI: 6.1-21.6), followed by gastrointestinal bleeding (adjusted OR 9.2, 95\% CI: 4.4-18.9) and recurrent stroke (adjusted OR 5.4, 95\% CI: 3.1-9.3). 
Table 2 - Patients' characteristics in particular periods.

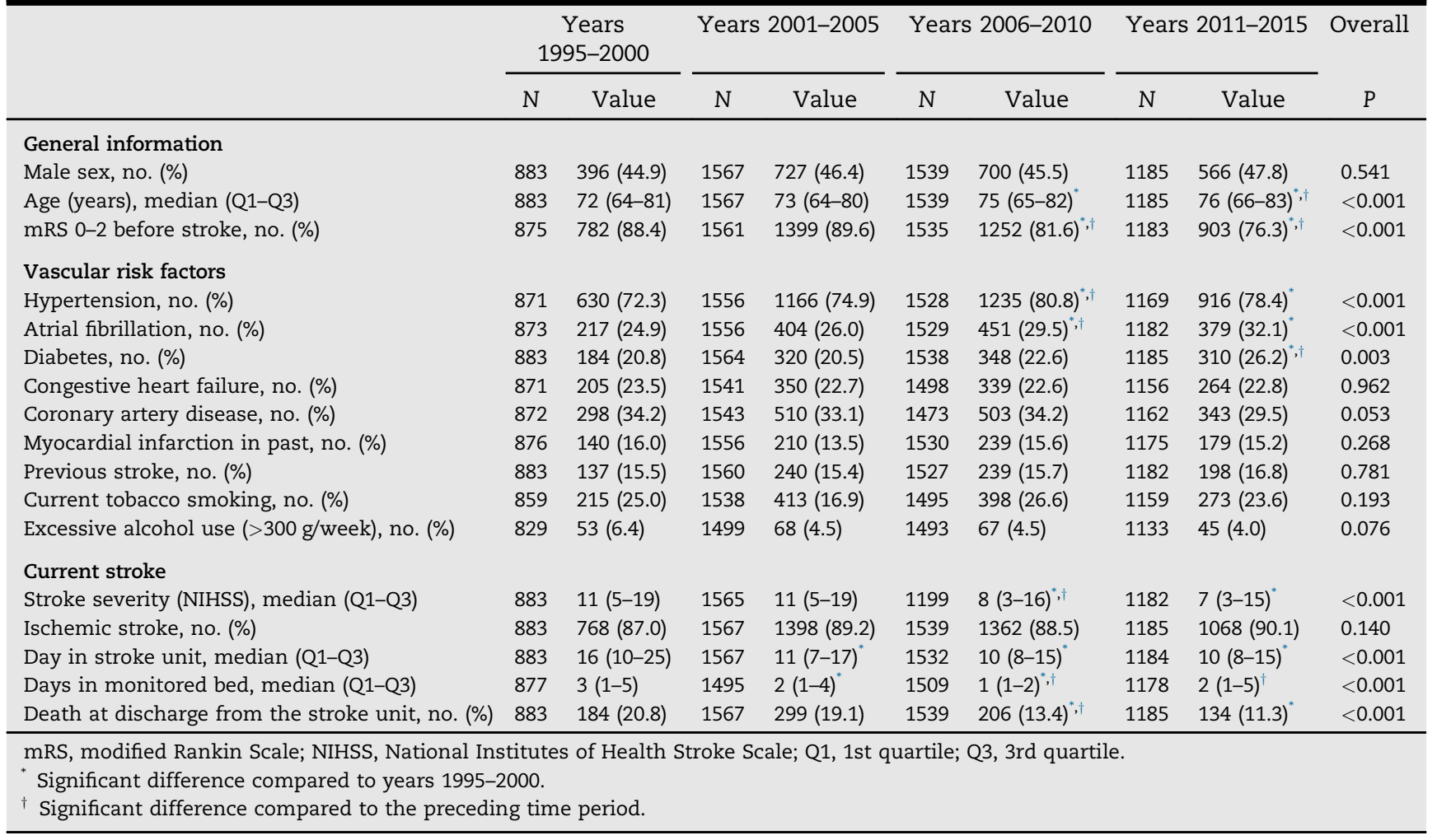

Table 3 - Noninfectious complications developed in stroke unit in particular time periods.

\begin{tabular}{|c|c|c|c|c|c|c|c|c|c|}
\hline & \multicolumn{2}{|c|}{$\begin{array}{c}\text { Years } \\
1995-2000\end{array}$} & \multicolumn{2}{|c|}{$\begin{array}{c}\text { Years } \\
2001-2005\end{array}$} & \multicolumn{2}{|c|}{ Years 2006-2010 } & \multicolumn{2}{|c|}{ Years 2011-2015 } & \multirow{2}{*}{$\begin{array}{c}\text { Overall } \\
\text { P }\end{array}$} \\
\hline & $N$ & Value & N & Value & $N$ & Value & $N$ & Value & \\
\hline Deep vein thrombosis, no. (\%) & 880 & $40(4.6)$ & 1558 & $42(2.7)^{*}$ & 1536 & $19(1.2)^{*}, \dagger$ & 1175 & $13(1.1)^{*}$ & $<0.001$ \\
\hline Pulmonary embolism, no. (\%) & 880 & $12(1.4)$ & 1558 & $21(1.4)$ & 1536 & $18(1.2)$ & 1175 & $16(1.4)$ & 0.963 \\
\hline Myocardial infarction, no. (\%) & 880 & $19(2.2)$ & 1558 & $22(1.4)$ & 1536 & $15(1.0)^{*}$ & 1175 & $3(0.3)^{*}+$ & 0.001 \\
\hline Exacerbation of congestive heart failure, no. (\%) & 880 & $40(4.6)$ & 1558 & $79(5.1)$ & 1536 & $40(2.6)^{*}$ & 1175 & $23(2.0)^{*}$ & $<0.001$ \\
\hline Gastrointestinal bleeding, no. (\%) & 880 & $0(0.0)$ & 1558 & $26(1.7)^{\circ}$ & 1536 & $29(1.9)^{*}$ & 1175 & $9(0.8)^{*}$ & $<0.001$ \\
\hline Seizure, no. (\%) & 880 & $3(0.3)$ & 1558 & $5(0.3)$ & 1536 & $6(0.4)$ & 1175 & $7(0.6)$ & 0.701 \\
\hline Recurrent stroke, no. (\%) & 880 & $8(0.9)$ & 1558 & $36(2.3)$ & 1536 & $22(1.5)$ & 1175 & $25(2.1)^{*}$ & 0.050 \\
\hline Pressure sores no. (\%) & 880 & $28(3.2)$ & 1558 & $25(1.6)^{\circ}$ & 1536 & $17(1.1)^{*}$ & 1175 & $27(2.3)^{\dagger}$ & 0.002 \\
\hline
\end{tabular}

\section{Discussion}

Reported data directly addresses the issue of noninfectious medical complications experienced by acute stroke patients admitted to a single stroke unit over a period of 20 years, which allowed to collect enough cases to make calculation of adjusted odds for hospital death relatively valid and robust. The study was carried out in a homogenous cohort of patients that may be considered representative for urban populations of Poland and other Central and Eastern European countries after economic transition.

Over the last two decades the occurrence of some noninfectious complications in our stroke unit (i.e. MI, DVT, exacerbated CHF) significantly decreased, whilst the occurrence of other complications remained relatively stable or fluctuated. There are probably multiple factors that contributed to this reduction, including improved infrastructure, introduction of intravenous thrombolysis, improved prestroke management of comorbidities, better general medical and nursing care. The decrease in hospital mortality may have resulted from better management of those complications combined with lower stroke severity. However, one should also note the $10 \%$ absolute reduction of the occurrence of hospital infections (data not published).

According to our findings cardiac complications seem to be the most important predictors of stroke unit death, both in terms of strength of association and their occurrence. Previous 
Table 4 - Odds ratios (ORs) for stroke unit death in particular time periods.

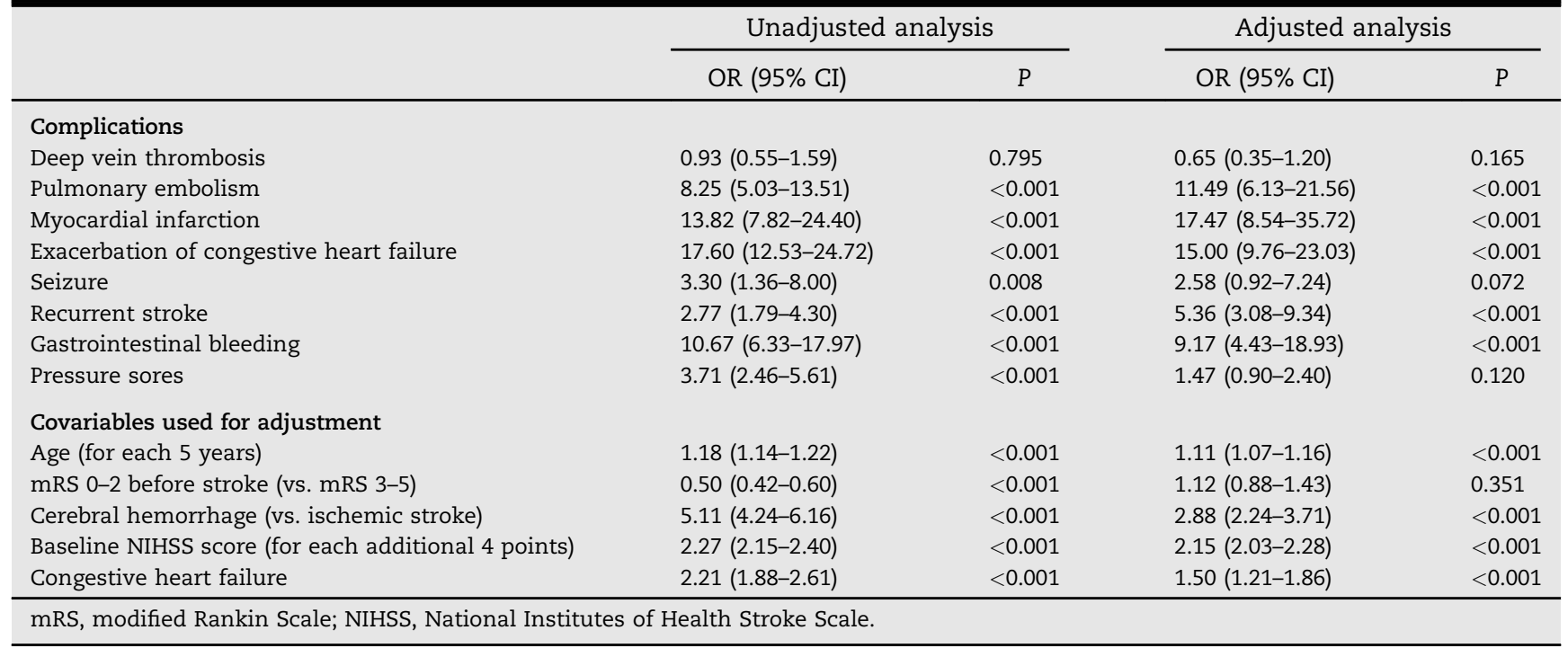

studies showed that MI may affect $0.5 \%$ to $6.0 \%$ acute stroke patients $[2,7,9,14,15,17]$ and increases risk of hospital death and non-cardiac complications [17]. The occurrence of MI in our cohort clearly decreased over time, which follows the pattern observed in Norway between year 2003 and 2013 [14] but not in the United States of America (years 1998 to 2007 for ischemic stroke and years 2004 to 2014 for cerebral hemorrhage hospital admissions) [7,15]. Exacerbated CHF was reported in $0.6 \%$ to $11 \%$ of acute stroke patients, which probably reflects difficulties in defining this particular condition $[2,10]$. We found a significant decrease of its occurrence between years 2001-2005 and years 2006-2010. One may speculate that continuous patient monitoring allows to detect early signs of cardiac ischemia or tachyarrhythmia that can be effectively managed before leading to more serious complications [14]. If we consider infrastructural and educational gains from the contemporary National Cardiovascular Disease Prevention and Treatment Program in Poland, this may be the major reason of this phenomenon [23].

Our data confirm that $\mathrm{PE}$ is a strong and independent predictor of hospital death [6]. The occurrence of PE was slightly higher than in other reports $(0.2-1.0 \%)[2,6-10,15]$ and it remained stable throughout the study period, conversely to slight but significant increase observed in the United States of America [7]. In the same time, the occurrence of DVT in our cohort gradually decreased from $4.6 \%$ to $1.1 \%$, which again is not in line with data from the United States [7,15]. This discrepancy may indirectly reflect the change that in prophylactic approach, as well as growing prevalence and better detection in the United States [7,24]. Overall, our results fit in the range of occurrence reported by other groups (0.2-4.0\%), and do not support uncertain association between DVT and the risk of death [2-4,6-11,15].

In the literature the rates of early recurrence range from $0.5 \%$ to $18 \%$, depending on the setting and the duration of follow-up after the presenting stroke [8-10,12,13]. It has already been shown that recurrent stroke worsens 90-day outcome [12]. However, our study is the first to provide direct evidence that the recurrence which happens during the initial hospital stay independently decreases chances of being discharged alive.

Previously reported rates of gastrointestinal bleeding were higher (2.0-5.0\%) than in our study $[2,6,9,10]$. However, our data fully support its strong association with hospital death described by Wang and colleagues [6].

The occurrence of pressure sores ranged in our cohort from $1.1 \%$ to $3.2 \%$ without a clear trend over time, which is in line with other studies ( 0.3 up to $21 \%$ after inclusion of subacute patients) [2-4,6,8-11]. It is not clear whether pressure sores independently predict poor outcome and our results do not support their independent association with hospital mortality $[6,10,11]$.

Seizures were observed in $0.3-0.6 \%$ of our patients, which complies with the lower limit of range reported in other studies (0.5-3.8\%, up to $23 \%$ if the subacute patients are included) $[9,10,13,16]$. The evidence about negative effect of post-stroke seizures on mortality is conflicting $[10,13]$. Our data suggest that such association may exist. However, it needs to be noted that statistical significance was lost after adjustment for confounders and the absolute number of cases was low $(n=21)$.

\subsection{Study limitations}

The study has several limitations that need to be noted. Data were collected in a prospective manner using a predefined questionnaire but the analysis is retrospective. The information about each patient was entered to the registry by the attending physician. Therefore we may not ensure that all reported events fully complied with provided definitions. However, to improve internal validity each paper questionnaire was checked and approved by the supervising stroke neurologist before digitization. Because of missing data in particular variables some cases had to be excluded from the adjusted analysis but considering large sample size, it was unlikely to bias the results. The registry does not include information about patient's ethnicity and place of residence. However, it may be reliably assumed that almost all participants were Caucasians living in a highly urbanized area. It should also be noted that each event was recorded only as a 
nominal variable. The registry does not contain information about its time of onset, duration, direct outcome and number of events if the complication occurred more than once. Ultrasound examination of lower extremities was not performed routinely, including patients who developed $\mathrm{PE}$ without clinical signs of DVT. It might have introduced bias toward lower occurrence of DVT but on the other hand clearly not all cases of ultrasound detected DVTs are clinically manifested or associated with the current stroke [25].

\section{Conclusion}

Our findings suggest that over the last two decades Polish urban stroke units achieved a significant reduction of the occurrence some noninfectious complications (i.e. MI, exacerbated CHF and DVT). It may have contributed to the decrease of stroke unit mortality. However, the list of complications that predict hospital mortality includes also PE, recurrent stroke or gastrointestinal bleeding. Therefore further efforts are needed to improve their prevention and management.

\section{Conflict of interest}

None declared.

\section{Acknowledgement and financial support}

We would like to thank our colleague neurologists from the Department who helped to perpetuate the registry throughout the years.

Funding: None.

\section{R E F E R E N C E S}

[1] Naghavi M, Wang H, Lozano R, Davis A, Liang X, Zhou M, et al. Global, regional, and national age-sex specific allcause and cause-specific mortality for 240 causes of death, 1990-2013: a systematic analysis for the Global Burden of Disease Study 2013. Lancet 2015;385:117-71.

[2] Kumar S, Selim MH, Caplan LR. Medical complications after stroke. Lancet Neurol 2010;9:105-18.

[3] Sauro K, Quan H, Sidkar K, Faris P, Jette N. Hospital safety among neurologic patients A population-based cohort study of adverse events. Neurology 2017;89:284-90.

[4] Ingeman A, Andersen G, Hundborg HH, Svendsen ML, Johnsen SP. Processes of care and medical complications in patients with stroke. Stroke 2011;42:167-72.

[5] Karliński M, Kobayashi A, Sobolewski P, Lisewski P, Romanowicz S, Fryze W, et al. Is there a bad time for intravenous thrombolysis? The experience of Polish stroke centers. Neurol Neurochir Pol 2014;48:45-51.

[6] Wang P-L, Zhao X-Q, Yang Z-H, Wang A-X, Wang C-X, Liu L-P, et al. Effect of in-hospital medical complications on case fatality post-acute ischemic stroke: data from the China National Stroke Registry. Chin Med J (Engl) 2012;125:2449-54.

[7] Tong X, Kuklina EV, Gillespie C, George MG. Medical complications among hospitalizations for ischemic stroke in the United States from 1998 to 2007. Stroke 2010;41:980-6.

[8] Ingeman A, Andersen G, Hundborg HH, Johnsen SP. Medical complications in patients with stroke: data validity in a stroke registry and a hospital discharge registry. Clin Epidemiol 2010;2:5-13.

[9] Ji R, Wang D, Shen H, Pan Y, Liu G, Wang P, et al. Interrelationship among common medical complications after acute stroke: pneumonia plays an important role. Stroke 2013;44:3436-44.

[10] Pandian JD, Kaur A, Jyotsna R, Sylaja PN, Vijaya P, Padma MV, et al. Complications in acute stroke in India (CAST-I): a multicenter study. J Stroke Cerebrovasc Dis 2012;21: 695-703.

[11] Ingeman A, Andersen G, Hundborg HH, Svendsen ML, Johnsen SP. In-hospital medical complications, length of stay, and mortality among stroke unit patients. Stroke 2011;42:3214-8.

[12] Rohweder G, Ellekjaer H, Salvesen O, Naalsund E, Indredavik B. Functional outcome after common poststroke complications occurring in the first 90 days. Stroke 2015;46:65-70.

[13] Balami JS, Chen R-L, Grunwald IQ Buchan AM. Neurological complications of acute ischaemic stroke. Lancet Neurol 2011;10:357-71.

[14] Bovim MR, Askim T, Lydersen S, Fjærtoft H, Indredavik B. Complications in the first week after stroke: a 10-year comparison. BMC Neurol 2016;16:133.

[15] Otite FO, Khandelwal P, Malik AM, Chaturvedi S, Sacco RL, Romano JG. Ten-year temporal trends in medical complications after acute intracerebral hemorrhage in the United States. Stroke 2017;48:596-603.

[16] Stefanidou M, Das RR, Beiser AS, Sundar B, Kelly-Hayes M, Kase CS, et al. Incidence of seizures following initial ischemic stroke in a community-based cohort: the Framingham Heart Study. Seizure 2017;47:105-10.

[17] Gattringer T, Niederkorn K, Seyfang L, Seifert-Held T, Simmet N, Ferrari J, et al. Myocardial infarction as a complication in acute stroke: results from the Austrian Stroke Unit Registry. Cerebrovasc Dis 2014;37:147-52.

[18] Foulkes M, Wolf P, Price T, Mohr J, Hier D. The Stroke Data Bank: design, methods, and baseline characteristics. Stroke 1988;19:547-54.

[19] Czlonkowska A, Ryglewicz D, Weissbein T, BaranskaGieruszczak M, Hier D. A prospective community-based study of stroke in Warsaw, Poland. Stroke 1994;25:547-51.

[20] Karlinski M, Bembenek J, Grabska K, Kobayashi A, Baranowska A, Litwin T, et al. Routine serum C-reactive protein and stroke outcome after intravenous thrombolysis. Acta Neurol Scand 2014;130:305-11.

[21] Gray LJ, Ali M, Lyden PD, Bath PMW. Interconversion of the National Institutes of Health Stroke Scale and Scandinavian Stroke Scale in acute stroke. J Stroke Cerebrovasc Dis 2009;18:466-8.

[22] von Elm E, Altman DG, Egger M, Pocock SJ, Gøtzsche PC, Vandenbroucke JP. The Strengthening the Reporting of Observational Studies in Epidemiology (STROBE) statement: guidelines for reporting observational studies. Lancet 2007;370:1453-7.

[23] Członkowska A, Niewada M, Sarzyñska-Długosz I, Kobayashi A, Skowrońska M. Ten years of stroke programmes in Poland: where did we start? where did we get to? Int J Stroke 2010;5:414-6.

[24] Bembenek J, Czlonkowska A. Venous thromboembolism prophylactic methods in acute stroke patients - current state of knowledge. Neurol Neurochir Pol 2013;47:564-71.

[25] Bembenek J, Czlonkowska A, Karlinski M, Kabayashi A. Early stroke-related DVT is more than just DVT diagnosed early after stroke onset. Thromb Res 2011;128:587-9. 